\title{
O HABEAS DATA NO SISTEMA JURÍDICO BRASILEIRO*
}

\author{
Dalmo de Abreu Dallari \\ Professor Titular do Departamento de Direito do Estado da \\ Faculdade de Direito da Universidade de São Paulo
}

\section{Resumo:}

O habeas data é garantia constitucional destinada a assegurar ao cidadão o acesso a dados que sobre ele constem dos registros públicos ou de órgãos de mesma natureza. Preliminares dos habeas data, sua presença na Constituição brasileira, o paradoxo da habeas data, além da especial apresentação do instituto na doutrina e Jurisprudência brasileira, é o que propõe o artigo.

\begin{abstract}
:
The habeas data is a constitucional guarantee destined to assure the citizen the access to basis referred to them that presents in publics registers or organs of the same nature. Preliminares of the habeas data, its presence in Brazilian Constitution, the paradoxe of habeas data, in addition to the special presentatio of this institute in Brazilian's doctrine and jurisprudence, this is what the article purposes.
\end{abstract}

Unitermos: habeas data; histórico; finalidade especifica; eficácia futura.

1. Preliminares do habeas data.

O habeas data é um tema novo no Direito brasileiro. Sua origem está ligada às circunstâncias políticas estabelecidas em conseqüência de um golpe militar, em 1964, e alteradas com a busca de restauração democrática através de uma nova Constituição, nos anos de 1987 e 1988. Na realidade, o habeas data não tem tradição no sistema jurídico brasileiro, tendo aparecido pela primeira vez na Constituição de 1988 , o que, de certo modo, facilita o trabalho dos pesquisadores, pois não existem trabalhos teóricos nem legislação ou jurisprudências anteriores a essa data.

Por outro lado, entretanto, como toda inovação, depende ainda do amadurecimento que só será obtido mediante a aplicação a casos concretos. No caso

* Trabalho apresentado no Seminario sobre Acción de Amparo y Habeas dala, realizado no Chile, na Facultad de Ciĉncias Juridicas y Sociales da Universidad de Talca, cm abril de 1997; atualizado cm julho de 2002. 
do habeas data brasileiro, é importante acrescentar que há, também, a necessidade de que sejam superados os fatores políticos que põem obstáculos à sua utilização. A partir daí deverá ocorrer a construção de uma doutrina, o que só será possível quando, através da Jurisprudência, forem revelados os pontos duvidosos e se fizer a construção do conceito, considerando os princípios e as normas fundamentais do sistema jurídico.

É importante registrar que antes da assembléia constituinte que elaborou a Constituição de 1988 nunca houve referência ao tema em obras doutrinárias brasileiras, não se conhecendo, também, qualquer proposta no sentido da criação de uma garantia constitucional dessa espécie antes de instalada a constituinte. Por esse motivo, na bibliografia jurídica brasileira não existem trabalhos de natureza teórica, prévios à Constituição, dedicados ao tema do habeas data ou dizendo algo a respeito de sua natureza, seu alcance e suas peculiaridades. E mesmo depois da vigência da Constituição, que foi promulgada em 5 de outubro de 1988, muito pouco foi escrito sobre o assunto. Em parte porque decorreu muito pouco tempo desde 1988 e, dentro desse período, outros temas ganharam maior relevância prática e por isso mereceram mais atenção dos constitucionalistas.

Mas, provavelmente, o motivo principal para a inexistência de uma contribuição teórica relevante seja, precisamente, a reduzida importância prática que se tem dado ao habeas data, o que pode parecer surpreendente ao estudioso que não conheça a História recente do Brasil e as características do ambiente político posterior a 1988. Para compreensão das peculiaridades do habeas data brasileiro e das circunstâncias que o tornaram menos importante do que se poderia supor, é necessário ter em conta alguns fatos e algumas particularidades do sistema jurídico e da realidade política brasileira. Será necessário ter em conta, também, a situação paradoxal do País nesse período, quanto ao sistema legal e à garantia dos direitos.

O Brasil sofreu um golpe militar, em 1964, e a partir desse ano teve vários governos militares, estabelecidos à margem da ordem constitucional. Nesse período houve quatro presidentes da República, todos generais do Exército e designados para a Presidência pelas Forças Armadas, tendo havido um breve período, entre o segundo e o terceiro desses presidentes, em que o governo foi exercido por uma junta militar. Dado o golpe de Estado e instalado um Governo militar em 1" de abril de 1964, foi publicado um Ato Institucional nome dado a uma proclamação militar arbitrária , segundo o qual continuaria em vigor a Constituição de 1946, mas com as limitações e restrições constantes do Ato Institucional, além de outras que fossem impostas pelo governo militar.

No ano de 1967 foi publicada nova Constituição, revogando-se formalmente a de 1946, mas os Atos Institucionais, complementados por outros atos normativos de origem militar chamados Atos Complementares, continuaram a ter precedência sobre a Constituição. Dois anos depois, em 1969, por motivo de uma dissidência entre os militares assumiu o Governo uma Junta Militar, que teve curta duração mas que durante seu Governo decretou uma nova Constituição, à qual foi dado, oficialmente, o nome de "Emenda Constitucional número l" para criar a 
impressão de continuidade do sistema militar. Evidentemente, nem o texto de 1967 nem o de 1969 tinham qualquer autenticidade como Constituições ou como emendas constitucionais, pois ambos foram feitos arbitrariamente, sem a mínima participação do povo.

Durante o período dos governos militares foi estabelecido e amplamente utilizado um sistema de informações sigilosas, tendo na cúpula o Serviço Nacional de Informações - SNI. Utilizou-se a tortura, a escuta telefônica, a corrupção, a falsificação de dados e de documentos e outros meios imorais e ilegais, para criar uma imagem negativa dos adversários do regime e para tentar justificar os assassinatos, as punições arbitrárias, as cassações e restrições de direitos, bem como a prática de violências e de corrupção pelos governantes e por seus aliados. Desse modo, foi construído um amplo registro de dados, quase todos falsos ou mentirosos.

Esses dados, sem nenhuma confiabilidade, foram muitas vezes utilizados para divulgações pela Imprensa ou mesmo para servir de base a processos administrativos ou judiciais. E nem as pessoas que figuravam nesses registros nem seus defensores legais, como também nem os juízes e tribunais, tinham acesso ao banco de dados, que era considerado sigiloso "por motivo de segurança nacional"

\section{O habeas data na Constituição brasileira.}

É bem fácil imaginar quanta infâmia, quantas injustiças, quantos atos de vingança pessoal, quanta busca de satisfação de interesses pessoais, quantos pretextos para a prática de violências e de resistência reacionária, quanta imoralidade e ilegalidade teve por único fundamento aquele banco de dados. É perfeitamente compreensível, portanto, que, no momento em que surgiu a possibilidade de restauração da proteção judicial dos direitos, tenha sido imaginada a criação de um instrumento especial para a quebra do sigilo dos dados existentes em mãos das autoridades de "segurança" e para a correção dos erros e das falsidades constantes de qualquer registro público ou em banco de dados passível de utilização para restringir, alterar ou eliminar direitos.

É importante assinalar que o direito à informação, em sentido amplo, já era reconhecido no Direito brasileiro. O que se tinha assegurado era o direito de obter informações que tivessem alguma relação com os direitos de uma pessoa, podendo esta solicitar tais informações para a finalidade genérica de "defesa de direitos" Em caso de negativa, o interessado poderia recorrer às vias judiciais, através do mandado de segurança, garantia constitucional de direitos existente no Sistema Jurídico brasileiro desde a Constituição de 1934.

Ressalve-se, porém, que o juiz poderia - e continua podendo, pela Constituição de 1988 - conceder mandado de segurança contra "ato ilegal de autoridade" que ofenda "direito líqüido e certo" do interessado. Como não se tinha vivido, ainda, uma situação em que a utilização maliciosa de dados contra os direitos dos cidadãos tivesse assumido as proporções trágicas verificadas depois de 1964, o problema, anteriormente, se limitava a casos particularizados de ofensa a direitos em 
decorrência de atos ilegais praticados por autoridades públicas. A par disso, como os registros policiais atingiam, quase sem exceção, a população pobre, incapaz de mobilizar a opinião pública, tinha-se como pacífico que tais registros deveriam ser sigilosos e, por esse motivo, não seria ilegal o ato de autoridade sonegando uma informação. E jamais se considerou grave, do ponto de vista político ou social, que tais registros contivessem informações falsas ou imprecisas.

Assim, pois, os antecedentes relativos ao direito à informação não haviam suscitado a necessidade de criação de um instrumento especial de proteção. E outros aspectos, novíssimos, relacionados com a informática e a mais moderna tecnologia de informações, passaram a ser considerados sob um ângulo próprio. Embora também possam afetar direitos da cidadania, são direitos reconhecidos e protegidos num ambiente de normalidade institucional e estão longe de assumir as dimensões dramáticas da utilização de dados para objetivos politicos num sistema ditatorial.

Considerando esses aspectos, a Constituição brasileira de 1988 incluiu entre os direitos e as garantias fundamentais, previstos no art. $5^{\circ}$, o direito à informação, mas é muito significativo que tenha dado a ele um tratamento diferente daquele que foi reservado especificamente aos dados que inspiraram a criação do habeas data. Com efeito, este foi objeto de um inciso próprio, o de número LXXII, de que se tratará mais adiante. $O$ direito genérico à informação está previsto no inciso XXXIII, do art. $5^{\circ}$, que tem a seguinte redação:

"Todos têm direito de receber de órgãos públicos, informações de seu interesse particular ou de interesse coletivo ou geral, as quais serão fornecidas no prazo da lei, sob pena de responsabilidade, ressalvadas aquelas cujo sigilo seja imprescindivel à segurança da sociedade ou do Estado"

Pode-se dizer que, embora se inclua também entre os direitos individuais, o direito à informação assumiu, no Brasil, muito mais as características de direito da coletividade, tendo, por tal motivo, meios próprios de proteção relacionados com essa concepção. Um ponto expressivo é que, quanto a esse direito à informação, a Constituição ressalvou expressamente a hipótese de sigilo por motivo de segurança, o que não ocorreu quanto às informações que podem ser objeto do habeas data. Ao lado de tudo isso, fica bem evidente que o legislador constituinte quis dar tratamento diferenciado às informações, de modo geral, as quais podem ser de interesse individual ou coletivo sem se referirem a dados pessoais, e àquelas outras relativas a determinadas pessoas.

Tendo em conta todos os elementos já mencionados, sobre sua origem e suas peculiaridades, pode-se afirmar que o habeas data foi criado no Brasil durante a elaboração da Constituição de 1988, tendo sido inspirado na recente utilização, por autoridades públicas, de dados inteiramente falsos ou contendo erros, visando a fins políticos e com grave prejuízo de direitos individuais.

Quanto à finalidade do habeas data, de acordo com o que ficou expressamente estabelecido, pode-se concluir que, em síntese, ele foi criado com dois objetivos, que constam do enunciado do art. $5^{\circ}$, inciso LXXII, da Constituição: 
“a. assegurar o conhecimento das informações relativas à pessoa do solicitante, constantes de registros ou bancos de dados de entidades governamentais ou de caráter público;

"b. para a retificação de dados, quando o interessado não prefira fazêlo por meio de processo sigiloso, judicial ou administrativo"

São essas as normas constitucionais que interessam para o exame do habeas data na concepção brasileira. Através delas pode-se ver com clareza que o habeas data foi criado com objetivos próprios, diferentes daqueles que inspiraram os meios de garantia do direito à informação, genericamente considerado. As particularidades da redação do inciso constitucional referente ao habeas data estão ligadas à sua origem, o que é fundamental que se tenha em conta na interpretação e aplicação desse dispositivo. Será oportuno, agora, verificar o que dizem os doutrinadores e qual a orientação da Jurisprudência, para mais completo conhecimento do assunto.

3. O paradoxo do habeas data: garantia para o passado.

Como já foi assinalado, o habeas data é novo no Brasil, em todos os sentidos. Por esse motivo é pequena a produção doutrinária sobre ele, não tendo sido publicada, até agora, uma obra dedicada exclusivamente a esse tema. O que se encontra são informações e breves comentários sobre o habeas data em trabalhos que se referem às garantias constitucionais de modo geral.

Pode-se dizer, sem temor de erro, que isso se deve ao fato de que não é grande o interesse dos juristas brasileiros pelo habeas data. Os autores que escrevem sobre garantias constitucionais não deixam de mencioná-lo, porque ele está expressamente previsto na Constituição, mas ninguém o considera da mesma importância prática do habeas corpus ou do mandado de segurança. Na realidade, a utilização do habeas data tem sido muito menor do que a esperada por seus criadores e pelos que trabalharam em defesa dos perseguidos políticos, o que demonstra que também por parte do povo, de modo geral, o interesse por essa garantia não é grande. Sobre isso é oportuno tecer algumas considerações.

A primeira razão do pequeno interesse pelo habeas data é o fato de ter sido superada a situação política que inspirou sua criação. Com efeito, numa circunstância em que as informações sigilosas eram intensamente utilizadas para negar direitos e justificar arbitrariedades havia enorme interesse na possibilidade de quebra do sigilo e na obtenção de informações sobre os dados registrados. Não existindo mais a situação em que as autoridades usavam dados falsos ou incorretos sem que houvesse a mínima possibilidade de que isso pudesse acarretar sua punição, aquelas mesmas pessoas que praticavam as violências e arbitrariedades passaram a agir com mais cautela, reduzindo-se substancialmente o uso de dados mentirosos.

A par disso, os que poderiam ser vitimas de novas falsidades sabem que agora contam com a proteção da lei e do Poder Judiciário, além disso, muitos dos que ontem foram vítimas hoje estão no Governo. Assim, não havendo a perspectiva de 
serem novamente prejudicados pela utilização de dados falsos, não há interesse em saber o que consta dos registros. Acrescente-se, ainda, o fato de que muitos dos antigos registros foram destruídos pelos que os utilizavam, justamente para não serem responsabilizados, após a restauração da normalidade jurídica.

Tudo isso torna de pouco interesse o acesso aos bancos de dados pessoais que foram utilizados para simulação de provas e para acobertar ilegalidades e que, teoricamente, alguém poderia tentar utilizar outra vez. Acrescente-se, afinal, que uma lei de anistia aprovada no final dos governos militares deixou livres de punição os que praticaram essas e outras arbitrariedades. E as vítimas, que sabem da impossibilidade de punir por via legal esses delinqüentes militares e civis, não querem viver em função de circunstâncias passadas e por isso a maioria nem procurou saber o que constava a seu respeito nos organismos que, ironicamente, eram identificados como "de segurança"

Quanto às razões prováveis para a pequena utilização do habeas data, uma palavra deve ser dita a respeito da timidez, ou coisa bem pior do que isso, dos tribunais superiores. Como se verá mais adiante, quando se cuidar da Jurisprudência, a orientação dos tribunais contribuiu muito para o esvaziamento do habeas data, assim como foi feito com o mandado de injunção, outra garantia constitucional criada em 1988 e praticamente anulada pelos órgãos superiores do Poder Judiciário. Os tribunais, inclusive o Supremo Tribunal Federal, têm-se mostrado muito resistentes à ampliação da proteção dos direitos fundamentais, em grande parte pelo excessivo conservadorismo de muitos de seus membros, mas também pela circunstância de que muitos deles foram levados aos tribunais pelos governos militares, exatamente porque aceitavam com docilidade, ou mesmo com entusiasmo, as ações arbitrárias.

Aí está, afinal, o grande paradoxo do habeas data. Ele teria sido de excepcional utilidade naqueles anos em que a violência e a corrupção se valiam amplamente de dados falsos para anular ou restringir direitos e para demolir reputações. Mas, certamente, se já existisse anteriormente o habeas data, ele teria sido suspenso pelos militares, que haviam usurpado o Governo e agiam arbitrariamente segundo suas próprias regras, não admitindo que suas "verdades" fossem contestadas. Foi precisamente isso que fizeram com o habeas-corpus, para impedir a soltura ou até a simples defesa de presos políticos vítimas de violência arbitrária.

Isso justifica o temor, quase a certeza, de que, se ocorrer um novo golpe de Estado, o habeas data não poderá ser utilizado, o que o torna inútil nos momentos em que prevalece a arbitrariedade e a utilização de dados falsos se torna prática rotineira.

4. O habeas data na doutrina e na Jurisprudência brasileiras.

Os doutrinadores brasileiros são unânimes em aceitar que não havia necessidade de uma lei complementar ou ordinária, nem de normas regulamentares, para aplicação dos dispositivos constitucionais relativos ao habeas data. Isso porque a Constituição estabelece, no parágrafo $1^{\circ}$ do art. $5^{\circ}$, que "as normas definidoras dos 
direitos e garantias fundamentais têm aplicação imediata." Entretanto, embora exista unanimidade relativamente a esse ponto, não se verifica a mesma unanimidade quanto a alguns aspectos particulares de grande importância prática.

O ideal seria que no futuro, quando houvesse mais experiência no uso do instituto e quando a Jurisprudência tivesse avançado, fosse feita uma lei eliminando as dúvidas sobre os pontos que poderiam suscitar controvérsias. Isso foi feito, há meio século, com relação ao mandado de segurança e, em princípio, não trouxe prejuizos e foi benéfico para a utilização mais uniforme da garantia constitucional. Entretanto, algumas alterações na lei relativa ao mandado de segurança restringiram seu alcance, em situações de interesse do Governo, o que deveria servir de alerta para que não se fizesse o mesmo com o habeas data, sob pretexto de facilitar sua aplicação.

Desinteresse generalizado pelo habeas data facilitou o assalto dos que se valeram das informações sigilosas como arma política, no último período ditatorial, e que, certamente, esperam fazer ainda tal utilização no futuro. Assim, no final de 1997, sem um alerta dos políticos ou da Imprensa, foi aprovada pelo Congresso Nacional e sancionada pelo presidente da República uma lei regulamentando o uso do habeas data. Essa lei, de número 9507, datada de 12 de novembro de 1997, contém redação maliciosa, que poderá ser usada para restringir o alcance do habeas data, além de não ter esclarecido as principais dúvidas já suscitadas.

O ponto claramente malicioso está no art. $1^{\circ}$ da lei, que do projeto constava como parágrafo único deste artigo, o qual estabeleceu que se consideram de caráter público, e portanto sujeitas ao habeas data, as informações "que não sejam de uso privativo do órgão ou entidade produtora ou depositária das informações". Podese considerar hipócrita ou cínica essa ressalva, pois os órgãos "de segurança" ou policiais sempre dirão que as informações constantes de seus registros são para seu "uso privativo", pois além de se ter aí uma expressão muito vaga e ambígua, foram esses órgãos que praticaram muitas violências escudados em informações falsas. Desse modo, a lei regulamentadora restringiu o alcance do habeas data e não deu qualquer contribuição para o esclarecimento das dúvidas mais relevantes manifestadas por doutrinadores e juízes.

As principais dúvidas e controvérsias relativamente à interpretação e aplicação do inciso LXXII, do art. $5^{\circ}$ da Constituição, que trata do habeas data, podem ser assim resumidas:

a. Quem pode utilizar o habeas data? O direito de ação cabe exclusivamente à pessoa a quem se referem os dados ou pode ser exercido por alguém que a represente?

Nos termos da Constituição, será concedido o habeas data para assegurar o conhecimento de informações "relativas à pessoa do impetrante" Não existe, propriamente, uma discussão a respeito desse ponto, mas a controvérsia surgiu a partir da afirmação textual de José Afonso da Silva de que o habeas data é um direito 
personalíssimo, que "morre com o titular" (Curso de Direito Constitucional Positivo, São Paulo, Revista dos Tribunais, 1989, pp. 391/2).

Hoje se tem conhecimento seguro de que muitos presos políticos foram assassinados nas prisões, por torturadores militares e civis. $\mathrm{Na}$ época em que foram mortos as autoridades distribuíram notas à Imprensa, informando que se tratava de suicídio ou de morte num confronto armado entre grupos subversivos e agentes da segurança ou mesmo num confronto entre grupos subversivos rivais. Em quase todos os casos as vítimas da repressão eram apresentadas como terroristas e assassinos impiedosos, afirmando-se que nos arquivos dos organismos de segurança havia provas das circunstâncias da morte e de que o morto era, realmente, um criminoso feroz.

Houve casos em que familiares dos presos assassinados inclusive a mãe de um deles - impetraram o habeas data, invocando sua condição legal de sucessores e de guardiães legítimos da memória do falecido. Pretendiam ter acesso aos dados relativos à data, ao local e às demais particularidades da morte, bem como aos dados relativos às atividades do morto, que as autoridades afirmaram ser comprovadamente um criminoso. Nesses casos não chegou a haver julgamento, porque o tribunal se recusou a considerar o pedido e o rejeitou liminarmente, por entender que o habeas data é direito personalíssimo, que, como escreveu José Afonso da Silva, morreu com o titular

Em face dessa orientação dos tribunais, reiterada em vários casos, os familiares das vítimas assassinadas deixaram de ingressar em juizo com pedido de habeas data. Esse é um dos exemplos de esvaziamento do instituto pelos tribunais. É possivel que uma discussão doutrinária acabe influindo para mudar a orientação do Judiciário, mas a falta de interesse pelo habeas data, anteriormente referida, vem adiando essa discussão.

b. Existe necessidade de um pedido prévio de acesso aos dados pelas vias administrativas ou o interessado pode ir diretamente ao Judiciário, por meio do habeas data?

A respeito da necessidade de tentar, previamente, obter os dados pela via administrativa e só em caso de resistência impetrar o habeas data, a opinião praticamente unânime dos doutrinadores é no sentido de que não existe essa necessidade, podendo o interessado ingressar diretamente no Judiciário. Entretanto, a Jurisprudência firmou-se em sentido contrário, como se verá em seguida, e a recente lei regulamentadora do habeas data praticamente encampou a orientação jurisprudencial predominante. Entretanto, pela relevância desse ponto e para mais completo conhecimento do assunto, será interessante reproduzir a polêmica.

Entre os trabalhos doutrinários que fazem referência ao habeas data merece especial atenção o livro Tutela Constitucional das Liberdades, de Vicente Grecco Filho (São Paulo, Ed. Revista dos Tribunais, 1989). Embora não tenha feito um estudo aprofundado e exaustivo do habeas data, o autor, que é especialista em Direito Processual Civil, enfocou objetivamente os pontos principais. Quanto à questão ora em exame, 
afirma Grecco que "a impetração (do habeas data) não depende de prévio pedido administrativo" E acrescenta que "mesmo no caso de retificação de dados prevista na alinea " $b$ " do dispositivo constitucional, a providência prévia administrativa é facultativa", ou seja, o interessado poderá, se quiser, pedir previamente à Administração Pública a retificação de dados, se já tiver conhecimento da existência de erros. Mas mesmo nesse caso poderá ir diretamente ao Judiciário, se preferir esta via.

A necessidade ou não de prévia utilização da via administrativa foi amplamente discutida no habeas data impetrado em 1989 perante o Superior Tribunal de Justiça pelo ex-deputado Airton Esteves Soares, que na condição de advogado tinha sido um dos mais ativos defensores de presos políticos e queria saber o que constava, a seu respeito, dos registros do Serviço Nacional de Informações (SNI). A resistência da Administração Pública em prestar as informações ficou bem evidenciada, nesse caso, no parecer do consultor geral da República, que se manifestando no processo do habeas data a respeito do pedido do interessado, disse, entre outras coisas, o seguinte: "A revelação (disclosure) dos dados pessoais existentes nos registros desse órgão será possivel, a juizo do Ministro-Chefe do Serviço Nacional de Informações, se o ato não se revestir de potencialidade danosa de valor politico-juridico posto sob cláusula constitucional de reserva: a segurança da sociedade e do Estado"

Com base nesse parecer, o ministro Ilmar Galvão, que participou do julgamento e foi voto vencido, considerou "fora de dívida, não apenas que a autoridade impetrada só irá fornecer ao requerente os dados que entender conveniente fazê-lo, mas também que não se sentirá obrigada a declarar se outros existem, sejam sigilosos, sejam não sigilosos. Desenganadamente, como indica o bom-senso, silenciará a respeito, deixando o interessado na ignorância dos ditos fatos e, mais ainda, impossibilitado de demonstrar o seu interesse de agir, e, conseqüentemente, de propor qualquer ação"

Essa foi uma excelente oportunidade, para o Poder Judiciário mostrar sua independência e deixar afirmado para as autoridades do setor de segurança que a situação do País havia mudado e que as garantias constitucionais eram efetivas. Bem ao contrário disso, nesse e em outros casos os tribunais superiores mostraram grande timidez e deram seu aval para que autoridades policiais continuassem a decidir arbitrariamente, acobertando as falsificações e os erros propositais ou involuntários contidos nos registros de dados. Com efeito, apesar da clara advertência do Ministro Ilmar Galvão quanto à má-fé da autoridade administrativa, o Superior Tribunal de Justiça estabeleceu a seguinte orientação jurisprudencial:

"Habeas data. Conhecimento. O habeas data é ação constitucional. Submete-se, por isso, às respectivas condições, entre as quais o interesse de agir. Processualmente, significa necessidade de ingresso em juizo, dada a resistência da contraparte. Faltará, entretanto, essa condição, se quem deveria prestar as informações ou promover a retificação de dados não as negou, porque nada lhe fora requerido. Inexiste, pois, lesão cıo direito do impetrante" (Decisão por maioria de votos, de 13 de junho de 1989, no Processo de habeas data número 4-DF - Revista Sup. Trib. Just., Brasília, 2(16):25-56, dez.1990). 
Para os advogados brasileiros, de modo geral, não foi supresa essa atitude da maioria dos membros do Superior Tribunal de Justiça, pois esse e outros tribunais superiores, inclusive o Supremo Tribunal Federal, têm tradição de se apegarem a formalidades processuais, decidindo questões preliminares de tal modo que não seja necessária uma decisão sobre o mérito, sempre que o caso contenha graves implicações políticas. No caso do habeas data essa é a Jurisprudência predominante: os tribunais exigem que o interessado, previamente, solicite os dados à autoridade administrativa, embora se saiba que esta irá alegar necessidade de sigilo, ou então fornecerá informações incompletas ou, simplesmente, dirá que o pedido não é claro quanto aos dados desejados. E qualquer dessas alegações tem sido aceita pelos tribunais como razão suficiente para que os dados não sejam fornecidos, o que permite afirmar, sem exagero, que o Poder Judiciário é fortemente responsável pelo esvaziamento do habeas data.

A Lei n. 9507, de 12 de novembro de 1997, regulamentadora do habeas data, tomou posição sobre esse aspecto, estabelecendo que a petição inicial do habeas data deverá ser instruída com a prova da recusa de fornecimento da informação, ou, se for o caso, da recusa de fazer a retificação ou anotação. Assim dispondo, a lei consagrou a via mais dificil para os interessados, pois a prova da recusa só poderá ser feita se for tentada previamente a via administrativa, o que poderá significar embaraços e retardamento, além de ser de duvidosa constitucionalidade essa exigência posta por lei ordinária.

c. A alegação de necessidade ou conveniência de manter em sigilo os dados solicitados, feita pela autoridade administrativa, é justificativa suficiente para que seja negado o habeas data?

Como já foi anteriormente assinalado, o que inspirou a criação do habeas data foi o forte desejo de ter acesso aos registros de dados dos organismos ditos "de segurança" para desmascarar a fabricação e utilização de dados falsos, utilizados de muitas formas contra os opositores do regime antidemocrático. Por motivos óbvios, aqueles registros eram classificados como sigilosos, para que as falsidades não fossem denunciadas e para que se mantivesse a imagem de registros muito completos, rigorosos e honestos.

Com a restauração da normalidade constitucional e a criação do habeas data, as vítimas, concretas ou potenciais, da utilização de dados falsos pensaram que já não coubesse a alegação de sigilo. Entretanto, através de várias manifestações de autoridades administrativas ligadas aos organismos de segurança, sobretudo militares, ficou evidente que o problema não estava superado, pois a alegação de sigilo, que antes era feita sob pretexto de "segurança nacional", continuou a ser usada, agora sob pretexto de segurança da sociedade e do Estado, para casos em que não cabe essa ressalva.

Por esse motivo vários doutrinadores que escreveram sobre o habeas data dedicaram atenção ao problema. Um ponto importante, na consideração do 
problema do sigilo, é a distinção, que tem base no texto constitucional, entre o direito à informação, de interesse individual ou coletivo, previsto no inciso XXXIII, do art. $5^{\circ}$ da Constituição, e o direito a informações pessoais, protegido pelos habeas data, estabelecido no inciso LXXII, do mesmo artigo.

Quanto ao primeiro desses direitos, o de caráter geral, diz a Constituição que ficam "ressalvadas aquelas (informações) cujo sigilo possa ser imprescindivel à segurança da sociedade e do Estado." Embora nem toda informação de interesse individual ou coletivo seja de caráter sigiloso, as autoridades policiais e militares têm o vício do sigilo, provavelmente por julgarem que isso dá maior prestígio às suas atribuições, mas também porque isso ajuda a esconder suas arbitrariedades e sua corrupção. Assim, consideram que tudo o que fazem é sigiloso, o que muitas vezes poderá levar à negativa da informação sem justificativa. Nesse caso o meio judicial para solução do problema será o mandado de segurança, cabendo ao Judiciário avaliar o pedido e a razão invocada pela autoridade para a ocultação do dado solicitado.

Quando se tratar do direito a informações pessoais, previsto no inciso LXXII, não cabe a invocação do sigilo e o interessado pode usar o habeas data para que a autoridade administrativa seja obrigada a fornecer os dados. A distinção entre as duas hipóteses constitucionais de direito à informação é feita com muita clareza por Vicente Grecco Filho, com estas palavras: "O direito às informações sobre a própria pessoa é incondicionado, não se aplicando, portanto, a ressalva do sigilo prevista no inciso XXXIII. O sigilo a que se refere este último dispositivo é cabivel em se tratando de informações objetivas, cuja divulgação possa comprometer a segurança da sociedade ou do Estado, mas em nenhuma hipótese pode ser negada informação pessoal para o próprio requerente" (ob. cit., p.175).

No mesmo sentido é o ensinamento de Michel Temer, que afirma incisivamente: "Todos os dados referentes ao impetrante (do habeas data) devem ser fornecidos. Não valerá, na hipótese de habeas data, a alegação do sigilo em nome da segurança do Estado. No preceito referente ao habeas data não se verifica essa restrição (do inciso XXXIII). Não há como, em matéria de direito individual, uitilizar-se de interpretação restritiva" (Elementos de Direito Constitucional, São Paulo, Revista dos Tribunais, 1989, p. 212).

Opinião semelhante é manifestada por Manoel Gonçalves Ferreira Filho, que, embora aceite sem ressalvas o sigilo de dados de caráter geral, também distingue claramente as duas hipóteses: "As informações que se podem obter do Poder Público aqui tratadas (inciso XXXIII, do art. 5") são de caráter geral, concernentes às atividades múltiplas dos órgãos governamentais e, portanto, justificam a ressalva imposta. Tratase do direito à informação tão-somente. Aquelas que se pretendem obter mediante a impetração do habeas data (inciso LXXII) dizem respeito a dados relativos à pessoa do requerente que, obviamente, não admitem segredo em relação a ele" (Curso de Direito Constitucional, São Paulo, Saraiva, 1989).

Na realidade, a Constituição tratou de modo diferente as duas hipóteses de direito à informação, o que se pode verificar claramente pela simples leitura dos 
incisos XXXIII e LXXII, do art. $5^{\circ}$. No primeiro caso, relativo a informações de caráter geral, está expressamente prevista a hipótese de sigilo, mas apenas quando este for indispensável para a segurança da sociedade ou do Estado. No segundo caso, referente a dados pessoais, não existe a ressalva do sigilo para o fornecimento de dados ao interessado. A única menção a sigilo feita nesse inciso é encontrada na letra "b", apenas para estabelecer que o interessado pode preferir que a retificação de dados seja feita por processo sigiloso, quando quiser evitar a publicidade. Mas a autoridade não pode negar as informações ao interessado nem pode determinar o sigilo no processo de retificação.

Apesar dessa clareza, a Jurisprudência vai em sentido contrário e não é firme, deixando dúvidas quanto às hipóteses em que a informação poderá ser negada com base no sigilo. Decidindo um pedido de habeas data, o Superior Tribunal de Justiça, por maioria de votos, não tomou conhecimento do pedido porque a interessada não tinha tentado obter os dados previamente, por via administrativa, o que prejudicava o pedido por "ausência do interesse de agir", segundo a conclusão do Tribunal.

Além desse erro evidente - porque o interesse de agir não depende de pedido prévio à autoridade administrativa, sendo suficiente o desejo de obter os dados um dos argumentos do relator do processo, para fundamentar seu voto, apoiado pela maioria, foi o seguinte: "Frente à cláusula do "sigilo" (art. 5", XXXIII, C.F.), por indeclinável submissão ao interesse público (segurança da sociedade e do Estado), não é absoluto o direito de acesso às informações. Compete ao Judiciário examinar a alegação do "sigilo" avaliando de sua procedência ou não, compatibilizando a segurança do Estado com o direito à revelação das informações pretendidas" (decisão de 2 de fevereiro de 1989, no processo de habeas data número 00 l-DF; Rev. do Sup. Trib. Just., Brasília, 2(16):25-56,dez.1990). Como é óbvio, não tinha qualquer cabimento a referência ao inciso XXXIII, pois o habeas data é previsto no inciso LXXII, o que deixa patente que a referência ao sigilo foi mero pretexto para desencorajar o uso do habeas data.

Outra decisão contendo a mesma impropriedade foi tomada pelo Tribunal de Justiça do Estado de Minas Gerais, em 23 de junho de 1993. Os dados dessa decisão foram assim resumidos pelo próprio Tribunal: "Habeas data Informações sigilosas Interesse Público - Candidato a magistrado - Investigação sobre aspecto da vida moral e social - Inviolabilidade - Inteligência do art. 5" XXXIII, da Constituição Federal Denegação - Denega-se a ordem de habeas data, quando for impetrado por candidato a concurso de Magistrado, objetivando o acesso deste às informações colhidas sobre sua pessoa, em processo de investigação acerca dos aspectos da vida social e moral do mesmo, uma vez que tais informações são requisitadas por força de lei, com garantia de inviolabilidade, cuidando-se, portanto, de situação excepcional, que autoriza o sigilo da administração, para atender ao interesse público, consoante ressalva contida no art. 5" XXXIII, da Constituição Federal." (Minas Gerais II 14.06.94, pp. 01 - ementa oficial).

Como é evidente, não cabia, também nesse caso, a invocação do inciso XXXIII, pois ele não se aplica ao habeas data. Além disso, a informação obtida pelo Tribunal e que impedia o interessado de candidatar-se ao ingresso na Magistratura podia ser errada ou falsa. Por esse motivo, o Tribunal poderia manter sigilo sobre a 
fonte de informações, mas deveria ter dado a informação ao interessado, para que este pudesse defender-se, se fosse o caso. A alegação imprópria do sigilo ofendeu o direito à informação sobre dados do próprio interessado, assegurada pelo inciso LXXII do art. $5^{\circ}$, referente ao habeas data. A par disso, impediu o exercício do direito de defesa, não dando ao interessado a possibilidade de esclarecer os dados e, eventualmente, de se defender de acusações injustas. E assim o interessado ficou impedido de ingressar na Magistratura por motivo que não se ficou sabendo se era verdadeiro. Também nesse caso o Tribunal mostrou despreparo ou pouca disposição para dar efetividade à garantia do constitucional do habeas data.

Como ficou demonstrado, os doutrinadores brasileiros receberam bem o habeas data e compreenderam seu alcance, como instrumento para garantir a obtenção de dados de caráter pessoal. Mas os Tribunais parece que não conseguiram perceber a distinção feita pela Constituição entre os dados de caráter geral, que, eventualmente, podem ficar sujeitos ao sigilo, e os dados de caráter pessoal, que jamais poderão ser negados ao próprio interessado, não admitindo a alegação da necessidade de sigilo. Por essa incompreensão, ou, talvez, pela intenção de dar apoio aos organismos de segurança, a Jurisprudência não tem sido favorável ao habeas data.

Para que fique clara a inconsistência da orientação ainda predominante na Jurisprudência, relativamente ao sigilo como fundamento para negar o habeas data, basta lembrar que se trata da garantia de obtenção de dados sobre a própria pessoa e considerar duas hipóteses. Se os dados que constam dos registros forem verdadeiros, o interessado já terá conhecimento deles e, portanto, em relação ao interessado, não há sigilo que possa ser guardado ou quebrado. Se os dados forem falsos ou contiverem erros, não interessa ao Estado ou à sociedade manter a falsidade ou o erro, interessando mais, em sentido contrário, a correção dos dados.

Com o passar do tempo e a atenuação dos fatores políticos, bem como com o esclarecimento a respeito do verdadeiro sentido do habeas data, é provável que a alegação de sigilo perca a influência que tem agora e o habeas data possa ter eficácia como garantia constitucional.

A respeito desse ponto, pode-se dizer que a Lei n. 9507, de 12 de novembro de 1997, em nada contribuiu para esclarecimento do assunto. Mais grave do que isso, essa lei criou uma nova possibilidade de dúvida e controvérsia, pois não acolheu nem rejeitou a hipótese de alegação de sigilo necessário ou conveniente, silenciando quanto ao sigilo. E criou a possibilidade de negativa da informação sob pretexto de se tratar de registro de dados para uso privativo do órgão que o mantém.

5. O habeas data brasileiro: finalidade especifica e eficácia futura.

O habeas data, na concep̧̧ão brasileira, é garantia constitucional destinada a assegurar a uma pessoa o acesso aos dados que sobre ela constem nos registros públicos ou de natureza pública. Em decorrência das circunstâncias políticas que levaram à criação do habeas data como garantia constitucional, sua utilização ainda é restrita, 
em grande parte porque os tribunais superiores não asseguram sua eficácia e, pelo contrário, contribuem para desencorajar o seu uso.

Embora a doutrina seja escassa e a Jurisprudência não contribua para qualquer esclarecimento ou avanço, alguns pontos já podem ser considerados pacíficos, relativamente ao habeas data. Em primeiro lugar, ele não se destina a assegurar, genericamente, o direito à informação olı o direito à intimidade, como ocorre em vários países da América Latina que também introduziram, recentemente, o habeas data em seus respectivos sistemas juridicos. No caso do Brasil, a finalidade específica do habeas data é garantir que uma pessoa tenha acesso aos dados que, a seu respeito, constem de bancos de dados que sejam públicos ou de natureza pública.

Esses dados não podem ser negados ao interessado, sob alegação da conveniência de manter sigilo, mas a Jurisprudência é vacilante, ou mesmo resistente, a esse respeito, fazendo confusão entre os dados de caráter geral, eventualmente sujeitos ao sigilo, e os dados de natureza pessoal, que para a própria pessoa nunca poderão ser considerados sigilosos.

A eficácia plena da garantia do habeas data ainda não foi atingida no Brasil, em parte por influência das circunstâncias políticas que inspiraram a criação dessa garantia constitucional, sobretudo porque sua utilização suscita a idéia de confronto com os organismos militares e civis de segurança. Entretanto, apesar da pobreza doutrinária e do esvaziamento jurisprudencial, o habeas data tem um potencial ainda não-explorado, no sentido da proteção das pessoas quanto à utilização de informações existentes em bancos de dados e não relacionadas com atividades políticas.

Assim, por exemplo, existe no Brasil um Serviço de Proteção ao Crédito, que embora não seja público pode ser considerado de natureza pública, pela abrangência dos dados e por sua influência sobre toda a população. É provável que dentro de pouco tempo se comece a utilizar o habeas data para saber que dados constam desse registro e para eventuais correções. Em casos como esse o habeas data terá pleno cabimento e será, efetivamente, uma garantia para direitos individuais.

Como conclusão final, pode-se dizer que o habeas data brasileiro não obteve ainda a plenitude da eficácia que devem ter as garantias constitucionais. Mas, assim como aconteceu antes no Brasil com o habeas corpus e o mandado de segurança, a experiência, o desenvolvimento doutrinário e a melhor Jurisprudência deverão proporcionar o amadurecimento do instituto, com a eliminação das dúvidas e o conhecimento seguro de suas peculiaridades. E daí decorrerá sua consolidação como garantia constitucional dotada de plena eficácia.

São Paulo, julho de 2002.

Referência Bibliográfica.

DALLARI, Dalmo de Abreu, Os direitos fundamentais na Constituição brasileira,In Revista da Faculdade de Direito da Universidade de São Paulo, 1995, p.421-437. 
FERRAZ JR., Tércio Sampaio, Interpretação e estudos da Constituição de 1988, São Paulo, Atlas, 1990.

GRECCO FILHO, Vicente, Tutela Constitucional das Liberdades, São Paulo, Ed. Revista dos Tribunais, 1989.

SILVA, José Afonso da, Curso de Direito Constitucional Positivo, São Paulo, Ed. Revista dos Tribunais, 1989.

Periódicos:

Repertório IOB de Jurisprudência - Tributário, Constitucional e Administrativo, São Paulo, publicação quinzenal.

Revista do Superior Tribunal de Justiça, Brasília, publicação mensal. 